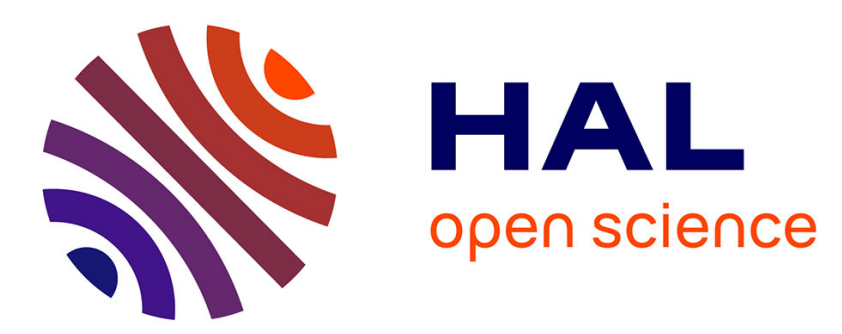

\title{
The effect of DEET on chemosensing of the honey bee and its parasite Varroa destructor
}

Nitin Kumar Singh, Nurit Eliash, Yosef Kamer, Ilya Zaidman, Erika Plettner, Victoria Soroker

\section{- To cite this version:}

Nitin Kumar Singh, Nurit Eliash, Yosef Kamer, Ilya Zaidman, Erika Plettner, et al.. The effect of DEET on chemosensing of the honey bee and its parasite Varroa destructor. Apidologie, 2015, 46 (3), pp.380-391. 10.1007/s13592-014-0330-1 . hal-01284453

\section{HAL Id: hal-01284453 \\ https://hal.science/hal-01284453}

Submitted on 7 Mar 2016

HAL is a multi-disciplinary open access archive for the deposit and dissemination of scientific research documents, whether they are published or not. The documents may come from teaching and research institutions in France or abroad, or from public or private research centers.
L'archive ouverte pluridisciplinaire HAL, est destinée au dépôt et à la diffusion de documents scientifiques de niveau recherche, publiés ou non, émanant des établissements d'enseignement et de recherche français ou étrangers, des laboratoires publics ou privés. 


\title{
The effect of DEET on chemosensing of the honey bee and its parasite Varroa destructor
}

\author{
Nitin Kumar SingH ${ }^{1}$, Nurit Eliash ${ }^{1,2}$, Yosef Kamer ${ }^{1}$, Ilya ZaIdman ${ }^{1}$, Erika Plettner ${ }^{3}$, \\ Victoria SOROKER $^{1}$ \\ ${ }^{1}$ Zrifin Apiary, Department of Entomology, Agricultural Research Organization; The Volcani Center, Institute of Plant \\ Protection, Bet Dagan, Israel \\ ${ }^{2}$ Institute of Agroecology and Plant Health, Robert H. Smith Faculty of Agriculture, Food and Environment, Hebrew \\ University of Jerusalem, Rehovot, Israel \\ ${ }^{3}$ Department of Chemistry, Simon Fraser University, Burnaby, BC V5A 1S6, Canada
}

Received 3 July 2014 - Revised 27 August 2014 - Accepted 10 October 2014

\begin{abstract}
Varroa destructor Anderson and Trueman (Acari: Varroidae) is an obligatory ectoparasitic mite of honey bees. In view of limited success in mite control, the use of synthetic repellent was evaluated. The objective of the present study was to investigate the effect of common arthropod repellent $\mathrm{N}, \mathrm{N}$-diethyl-m-toluamide (DEET) on the chemosensing of the $V$. destructor and its hosts, the European honey bee (Apis mellifera L.), by electrophysiological and behavioural bioassays. In electrophysiological assays, the nurse headspace served as a positive stimulus for the $V$. destructor foreleg, whereas a queen headspace was used as a positive stimulus for honey bee antennae. Two effects of DEET on $V$. destructor host chemosensing were evaluated: short-term inhibition and longterm inhibition. The inhibition observed in the presence of DEET simultaneously with a positive stimulus was termed "short term inhibition", while inhibition that occurred following the administration of the compound alone was termed "long term inhibition". In $V$. destructor, DEET served as a long-term inhibitor to the response of the chemosensory organ to nurse bee headspace volatiles, whereas in honey bee, it caused short-term inhibition of antenna response to queen volatiles. Consistent with electrophysiological studies, DEET significantly inhibited host choice of mites, whereas even a 10 times higher dose did not alter honey bee behaviours (e.g. antennating, grooming, fanning etc.) or worker attraction to a queen. These data suggest that DEET may selectively disrupt the honey bee chemosensing of $V$. destructor.
\end{abstract}

N,N-Diethyl-m-toluamide / Apis mellifera ligustica / electroantennogram / behavioural bioassay / short-term inhibitor / long-term inhibitor

\section{INTRODUCTION}

Varroa destructor Anderson and Trueman (Acari: Varroidae) is an obligatory ectoparasitic mite of honey bee (Apis mellifera and Apis cerana) and is considered to be one of the major causes of European honey bee (A. mellifera) colony losses almost worldwide (Rosenkranz et al. 2010). Transmission of viral diseases by the mites along with

Corresponding author: V. Soroker, sorokerv@volcani.agri.gov.il

Manuscript editor: Peter Rosenkranz rapidly developing resistance to acaricides makes $V$. destructor one of the major threats to apiculture and its control a great challenge. The life cycle of the mite is well synchronized with that of the honey bee and can be generally divided into two main phases: a phoretic phase, in which the mite can be found between the abdominal segments of the adult bee where they can reach the intersegmental membrane for feeding, and a reproductive phase, in which the mites reproduce within the sealed brood cell (Rosenkranz et al. 2010). The entrance of a fertilized $V$. destructor female into the brood cell is synchronized with the developmental stage of the larva and occurs shortly before the cell is sealed 
(Martin 2001). When the mites emerge from the brood cell with the new bee, they will attach to an older bee outside of the cell and ride around the colony on that bee. When adult mites are carried by foragers, they are able to disperse throughout the colony and beyond, whereas on top of nurses, mites may reach a new brood cell. Between these phases, the $V$. destructor moves freely on the surface of the comb. Several studies have indicated that chemical cues play a major role in the host finding and preference of the mites. In laboratory bioassays by Nazzi et al. (2001) and Pernal et al. (2005) have shown that $V$. destructor is capable for discriminating between bees from different task groups and to prefer a nurse over a forager. The host preference is apparently based on both low volatility compounds, such as cuticular hydrocarbons (Del Piccolo et al. 2010), and on volatile compounds emitted by the honey bees and their environment (such as larval food and brood pheromone) (Le Conte et al. 1989; Nazzi et al. 2001; Pernal et al. 2005). Despite much progress in the identification of host olfactory cues guiding $V$. destructor, neither effective attractants nor repellents have been found so far, stressing the importance of understanding chemical detection in V. destructor . Our approach to its control is disruption of synchronization between the mites' and honeybees' life cycle by interference in parasite host chemosensing.

The major olfactory organ of $V$. destructor is located on the distal part of its forelegs, analogous to the sensory pit (Haller's organ) found in ticks (Dillier et al. 2006). Recently, we were able to show that this organ serves for detection of honey bee volatiles (Eliash et al. 2014). Porous sensilae in the sensory pit are presumably responsible for sensing these volatiles (Dillier et al. 2006). Not much is known about the structure and function of this sensory organ. This is unlike insects such as honey bees, in which the antennae are the major olfactory organ. Structure and function of honey bee olfactory system was recently reviewed by Sandoz (2011).

Recently combining electrophysiology and behavioural assays, we identified some synthetic volatile compounds (dialkoxybenzenes and 5-2' hydroxyethyl-2-cyclopenten-1-ol ether derivatives) that disrupt host volatile sensing and selection by the $V$. destructor (Eliash et al. 2014). The question remains if it is possible to disrupt mite's chemosensing without any negative effect on honeybee chemosensing and thus colony function? As these compounds are still unavailable commercially, it was interesting to evaluate this question testing the effect of standard commercial repellent N,Ndiethyl-m-toluamide (DEET). The effect of DEET against a broad spectrum of arthropods, such as mosquitoes and ticks, is well known (Carroll et al. 2008; Klun et al. 2006; Stanczyk et al. 2010, 2013; Fabbro and Nazzi 2013). DEET is usually used as a contact repellent, but its long range effects have also been published (Ditzen et al. 2008; Lee et al. 2010; Syed and Leal 2008; Kain et al. 2013). However, its effect on mites and particularly on $V$. destructor has not yet been reported. The current study examined the effect of DEET on $V$. destructor and the honey bee, implementing both electrophysiological and behavioural assays.

\section{MATERIALS AND METHODS}

\subsection{Varroa and honey bees}

Honey bee colonies (A. mellifera ligustica) were maintained at an experimental apiary at The Volcani Center, Israel. The experimental hives were maintained without any treatment against mites. Female adult $V$. destructor were collected from a tray under a screen net at the bottom of the hive and were kept on a moist filter paper at room temperature up to $4 \mathrm{~h}$ prior to the experiments. Adult honey bees of two task groups (nurse and foragers) were collected for the experiments. Honeybees observed leaning into brood cells were regarded as nurse bees, whereas pollen foragers, carrying pollen loads, were collected from the entrance of the hive. One-year old queens were collected from hives at the time of queen replacement. The bees were killed by freezing at $-20^{\circ} \mathrm{C}$ for $1 \mathrm{~h}$ and thawed approximately for about $30 \mathrm{~min}$ before the start of the experiment. Prior to a behavioural bioassay, the pollen loads were thoroughly removed from forager bees by using forceps under stereo microscope (Olympus DF PLAPO 1XPF JAPAN). Nurses were used as collected from the hive.

\subsection{Electrotarsograms} and electroantennograms

The $V$. destructor foreleg and honey bee antennae were excised at the base and mounted between two 
glass capillaries filled with $\mathrm{KCl}$ solution $(0.1 \mathrm{~N})$, each containing a silver recording electrode, thus closing the electrical circuit. A constant flow of charcoalfiltered and humidified air was blown towards the organ at a rate of $100 \mathrm{~mL} / \mathrm{min}$ using a stimulus flow controller (model CS-05; Syntech, Hilversum, the Netherlands).

The effect of DEET on the electrophysiological response was measured relative to the response to a positive stimulus (bee headspace). The headspace was presented by puffing charcoal-filtered air $(1000 \mathrm{~mL} / \mathrm{min}$, for $1 \mathrm{~s}$ ) through a glass jar that contained freshly freezekilled five nurse bees as a positive stimulus for mite foreleg and one freeze-killed queen bee as a positive stimulus for bee antenna. The headspace of five nurse bees was chosen as a positive stimulus, because earlier dose-response studies showed that this was sufficient to elicit a maximal response (Eliash et al. 2014). The glass jars with freeze-killed bees were kept in a controlled environment $\left(32-34{ }^{\circ} \mathrm{C}, 62-70 \%\right)$. Headspace of an empty jar kept under the same conditions was used as control. The same foreleg or antennae were used to test all the doses.

\subsection{Preparation of electrophysiology cartridges}

To prepare electrophysiological cartridges for testing the repellence of DEET (Sigma Aldrich), $1 \mu \mathrm{L}$ of DEET dissolved in hexane (Merck, for spectroscopy) was pipetted onto a piece of filter paper (Whatman no 1) which was placed in a glass Pasteur pipette and exposed to air for $30 \mathrm{~s}$ to allow solvent to evaporate. Dose-response recordings were conducted on the mite's foreleg and bee antenna using $1-\mu \mathrm{L}$ solutions of DEET serially diluted 1:10 with hexane to yield concentrations of $100,10,1$ and $0.1 \mu \mathrm{g} / \mu \mathrm{L}$. Hexane was used as a control. The same sense organ was used to test the effect of all the doses from a lower $(0.1 \mu \mathrm{g})$ to a higher dose $(100 \mu \mathrm{g})$. The electrophysiological response of the sensory organ to a positive stimulus was measured relative to its response to air.

\subsection{Electrophysiology assay with Varroa forelegs and bee antennae}

To test the effect of DEET on the olfactory system of the $V$. destructor and honey bee workers, the response to three different stimuli was compared: a "positive stimulus", "positive stimulus + DEET/hexane" and, again, positive stimulus. In all experiments, the stimuli were administered in the same order on the same $V$. destructor foreleg or bee antenna as presented in Figure 1a, b respectively. At least six different mite forelegs and six different bee antennae were tested (one from each individual) for each experiment. The response of foreleg and antenna treated with stimulus "Air" and hexane was used as a control under the same conditions. The electrophysiological response $(\mathrm{mV})$ was amplified and recorded by a PC via an IDAC 232 for data acquisition using the "EAG 2000" and "GCEAD-2000" software (all Syntech). According to unpublished findings of Eliash (2012), for the organ to recover and to prevent adaptation, we allowed intervals of $30 \mathrm{~s}$ between each stimulus unless specified otherwise. The response amplitude for all data except dose response was normalized relatively to the response of the same organ to the average control stimulus using equation described below. Only individuals that showed a higher response to the positive stimulus than to air prior to the exposure to the DEET/hexane were used for statistical analysis.

Normalization equation Res - response amplitude to a stimulus (mV), Air - response amplitude to air $(\mathrm{mV})$ and $N$-response amplitude normalized relative to the response to air (\%).

$$
\begin{aligned}
N= & \frac{(\text { response to stimulus }- \text { response to air }(\text { control }))}{\text { response to stimulus }} \\
& \times 100+100
\end{aligned}
$$

\subsection{Effect of DEET on $V$. destructor behaviour}

Mite host preference was tested in a two-choice bioassay based on Kraus (1993) with a slight modification. Briefly, a single mite was placed in the centre of the arena (90-mm diameter and 17-mm deep glass petri dish) and was presented with a choice of a freshly killed forager and a nurse placed on the opposite sides of the arena. The experiments were conducted in a controlled dark environment, at $34-35{ }^{\circ} \mathrm{C}$ and $60-70 \%$ relative humidity (RH) (simulating conditions in a bee hive). The mite's choice was examined in the presence of 1,5 and $10 \mu \mathrm{g}$ of DEET dissolved in $1 \mu \mathrm{L}$ of hexane. The control used in this experiment was $1 \mu \mathrm{L}$ of pure hexane 

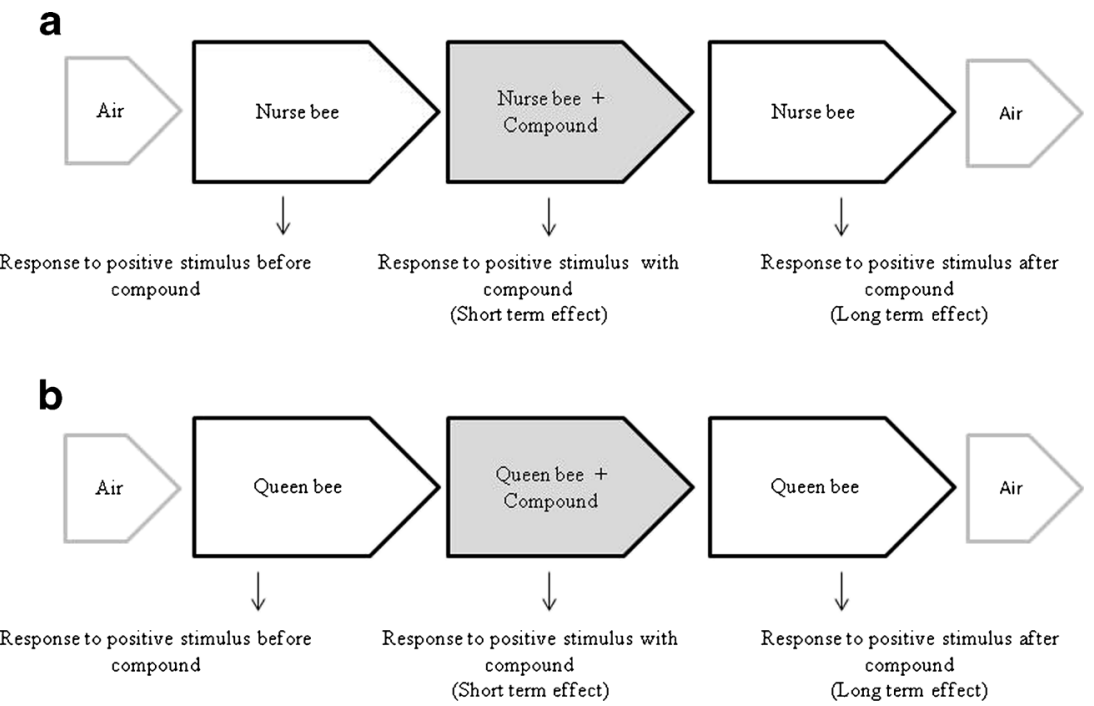

Figure 1. Stimulation order for electrotarsograms with Varroa destructor forelegs, electroantennograms with bees' antennae and terminology used for the corresponding responses. The time interval between each stimulus was $30 \mathrm{~s}$, unless otherwise stated. a The order of stimuli used on the mite's foreleg were air (control), five nurse bee headspace (positive stimulus), positive stimulus together with DEET or hexane (control), positive stimulus and again air. b The order of stimuli used on the bee antennae were air (control), queen headspace (positive stimulus), positive stimulus together with DEET or hexane (control), positive stimulus and again air. The level of the response to the positive stimulus with DEET or hexane (control) indicates the type and the level of short-term effect of a compound (DEET or hexane) on the host odour sensing. The level of the response to positive stimulus after exposure to a compound indicates the long-term effect.

as the DEET compound was dissolved in the hexane. The DEET or hexane was placed right above the mite on the inner side of the dish cover, on a piece of Parafilm $(5 \times 5 \mathrm{~mm}$, Bemis, USA) for slow release. Each dose was tested at least in three replicated experiments; in each experiment, 10 mites were tested for each treatment (DEET or hexane). $V$. destructor host preference between a forager and a nurse bee, and sum of mites reaching any of the hosts, was calculated as the percentage of total viable mites, after $120 \mathrm{~min}$ from the beginning of the experiment. The viability of mites was confirmed at the end of the experiment by touching it with the paint brush. Those that did not move following brush stimulation were considered dead and were excluded from the statistical analyses.

\subsection{Effect of DEET on honey bee behaviour}

Nurse bees leaning into brood cells were collected and chilled for $5 \mathrm{~min}$ at $4{ }^{\circ} \mathrm{C}$, individually marked with different colours (Posca, Japan) and allowed to recover at room temperature, for 2-3 $\mathrm{min}$. The experiments were conducted on five bee sets in a petri dish (150$\mathrm{mm}$ diameter and 20-mm deep) in the presence of $1 \mu \mathrm{L}$ of hexane containing 1,10 and $100 \mu \mathrm{g}$ of DEET placed on cotton wool wicks $(1 \times 1 \mathrm{~cm}) ; 1 \mu \mathrm{L}$ pure hexane was used for control. Each dose was tested at least in three replicates. The experimental set-up was kept in a controlled environment $\left(26-27^{\circ} \mathrm{C}\right.$ and $\left.35-50 \% \mathrm{RH}\right)$, and bees' behaviour was video recorded over a period of $10 \mathrm{~min}$. The video-recorded behaviour was analysed with the help of Perspective Birdy 1.0 software, coded by Perry, Y and Shellef, E.

\subsection{Effect of DEET on bee attraction to the queen}

To test the effect of DEET on the attraction of nurse bees towards the queen bee, a choice bioassay experiment was performed as described by Torto et al. (2013) with a slight modification. Briefly, 20 live nurse bees were placed in the centre of the arena on a disposable 
plastic petri dish (150-mm diameter and 20-mm deep). After $1 \mathrm{~min}, 100 \mu \mathrm{g}$ of DEET dissolved in $1 \mu \mathrm{L}$ of hexane or $1 \mu \mathrm{L}$ of pure hexane was placed on a piece of Parafilm $(5 \times 5 \mathrm{~mm}$, Bemis, USA $)$ in the centre on the inner cover plate. Subsequently, a choice of 1 freezekilled nurse bee and a 1-year-old queen bee was presented on the opposite sides of the arena. The experiments were conducted in a laboratory, at $25-27{ }^{\circ} \mathrm{C}$ and $45-50 \%$ humidity. The number of bees next to a queen or a nurse bee was recorded every $20 \mathrm{~s}$ for $10 \mathrm{~min}$.

\subsection{Statistical analysis}

For the electrophysiological assays, the normalized data in percentages were analysed using ANOVA repeated measures, followed by a Tukey-Kramer post hoc test unless specified otherwise. For behavioural assays, we used the chi-square test of goodness of fit to test the hypothesis that there was no significant difference in the total number of mites reaching nurse and forager bee. The same test was used for testing a possible effect of the DEET on Varroa ability to reach any of the hosts. Chi-square test for independence was used to compare the attraction of nurses to a dead queen and nurse, in the presence of DEET or hexane. All statistical procedures were carried out with the SAS JMP ${ }^{\circledR}$ Start statistic programme 7.0.2.

\section{RESULTS}

\subsection{Effect of DEET on the peripheral olfactory system of $V$. destructor and honey bee as detected by electrophysiology}

The electrophysiological bioassay was performed on the mite's foreleg and the bee antenna to determine the ability of these organs to detect DEET in comparison to the control hexane. The dose response of mites and bees differed. Only honey bee antennae showed a strong response to DEET which increased in a dosedependent manner with doses ranging from 0.1 to $100 \mu \mathrm{g}$ (Figure 2). Contrary to honey bees, $V$. destructor forelegs responded weakly to DEET in a more or less inconsistent manner (Figure 2). To test whether DEET can block host recognition by the mites, we evaluated its effect in combination with the positive stimulus: headspace of five nurses. Headspace of one queen bee was used as a positive stimulus to test the blocking effect of honeybee chemosensing. As can be seen in Figure 3a, DEET caused some inhibition albeit not significant in response of $V$. destructor leg to honey bee headspace when administered together with the latter, "short term inhibition". However, stronger and statistically

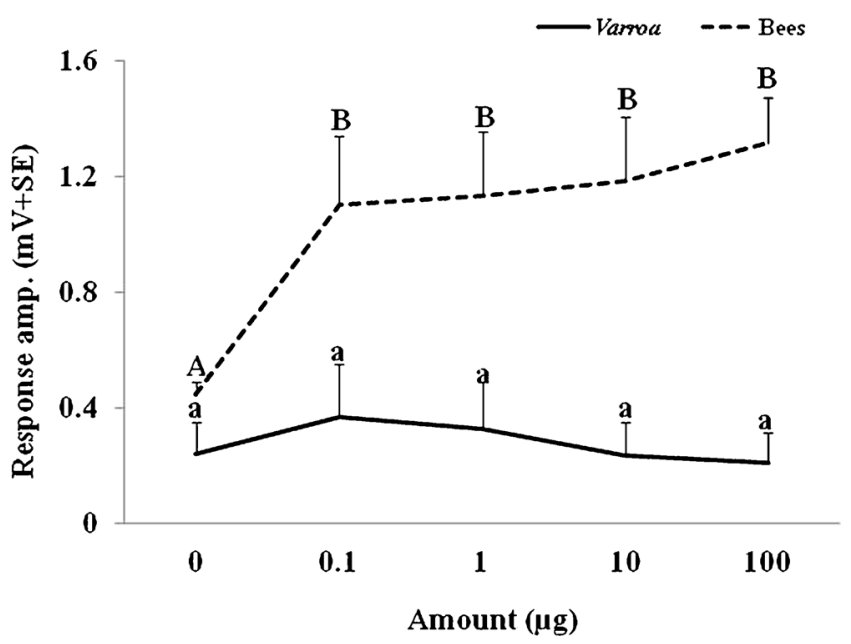

Figure 2. Electrophysiological dose responses of honey bee antennae and Varroa destructor foreleg to DEET. Results are average responses $+\mathrm{SE}$ of six bee antennae and seven Varroa forelegs, expressed in millivolts. Different letters (lower case for mites and upper case for honey bees) indicate significant differences in responses to ascending amounts. ANOVA repeated measures $P<0.05$, with Bonferroni correction. 

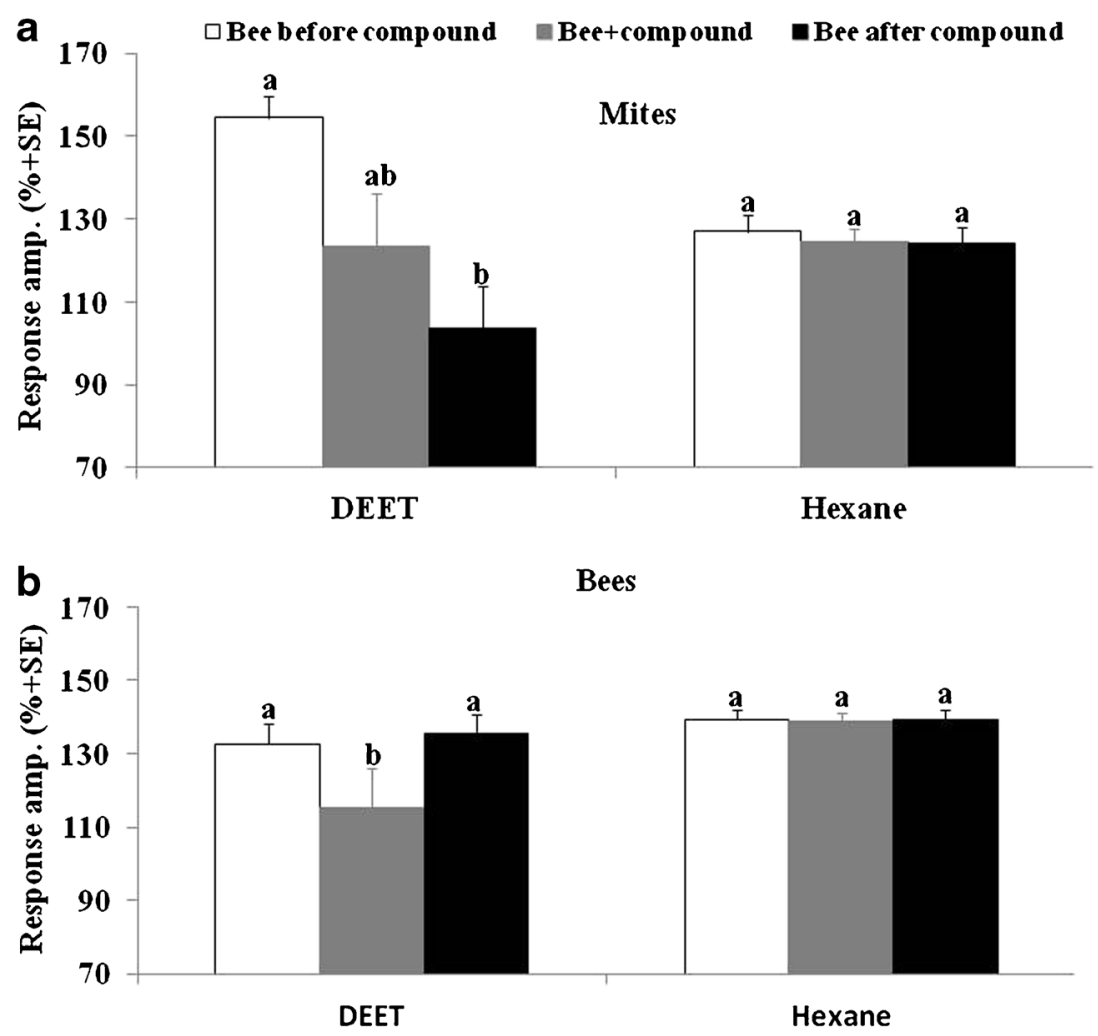

Figure 3. The effect of DEET on electrophysiological response of Varroa destructor foreleg and honey bee antennae. Each organ was tested with three sequential stimuli: positive stimulus (five nurse bee headspace for mite's foreleg or headspace of one queen for bee antenna), positive stimulus + DEET or hexane and another positive stimulus. a Effect of $10 \mu \mathrm{g}$ DEET in $1 \mu \mathrm{L}$ hexane or $1 \mu \mathrm{L}$ hexane (control) on mite's foreleg. b Effect of $10 \mu \mathrm{g}$ DEET in $1 \mu \mathrm{L}$ hexane or $1 \mu \mathrm{L}$ hexane (control) on honey bee antennae. The results are average normalized values $(\%$, average $+\mathrm{SE})$. Columns marked by different letters are significantly different, ANOVA repeated measures, followed by a post hoc Tukey-Kramer test, $P<0.05$. Varroa $n=6$, honey bee $n=6$.

significant inhibition occurred to the next, positive stimulus, nurse bee headspace volatiles $\left(F_{3,20}=\right.$ $5.58, P=0.006$, ANOVA followed by a TukeyKramer test). This type of response was termed long-term inhibition, according to Eliash et al. (2014). Both effects were specific to DEET as its solvent hexane did not cause any significant effect on response of the mite's foreleg to honey bee headspace $\left(F_{2,18}=0.1415, P=0.8690\right.$, ANOVA followed by a Tukey-Kramer test) (Figure 3a). The evaluation of honey bee antennae response to DEET revealed significant inhibition only when given together with queen volatiles, shortterm inhibition $\left(F_{3,18}=6, P=0.005\right.$, ANOVA followed by a Tukey-Kramer test) (Figure 3b). This effect was specific to DEET as its solvent hexane did not cause any significant inhibition of the response of the bee antennae $\left(F_{2,15}=0.0075\right.$, $P=0.9926$, ANOVA followed by a TukeyKramer test) (Figure 3b) as was previously shown for the $V$. destructor .

To evaluate the longevity of DEET inhibitory effect on the mite's foreleg, the time interval between the two sets of stimuli was manipulated, i.e. after the stimuli of "DEET/control hexane + nurse bee headspace", the next positive stimulus (pure nurse bee headspace) was administrated after either 30 or $90 \mathrm{~s}$. The results point out that the significant inhibiting effect of the DEET lasts for over $90 \mathrm{~s}\left(F_{3,20}=5.5, P=0.006\right.$, ANOVA followed by a Tukey-Kramer test) (Figure 4a). No significant electrophysiological effect was observed 
a

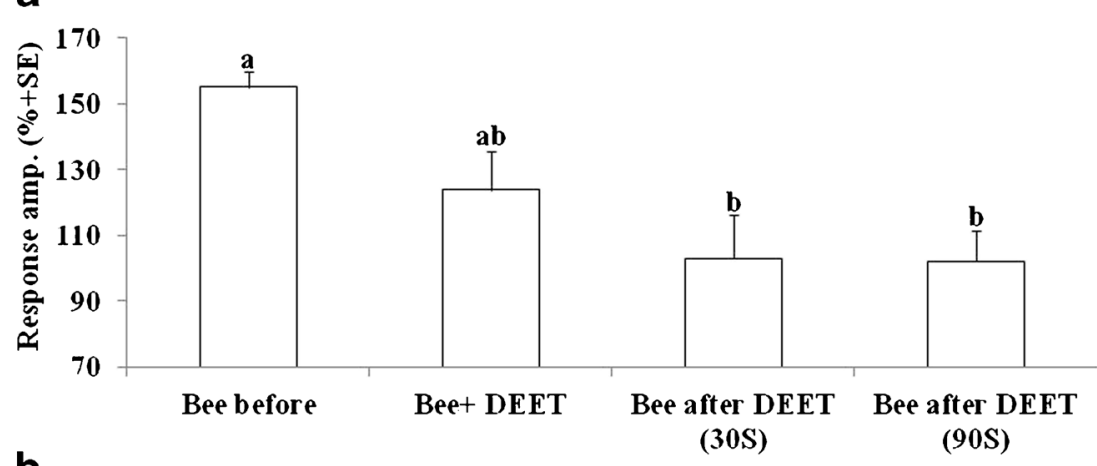

b

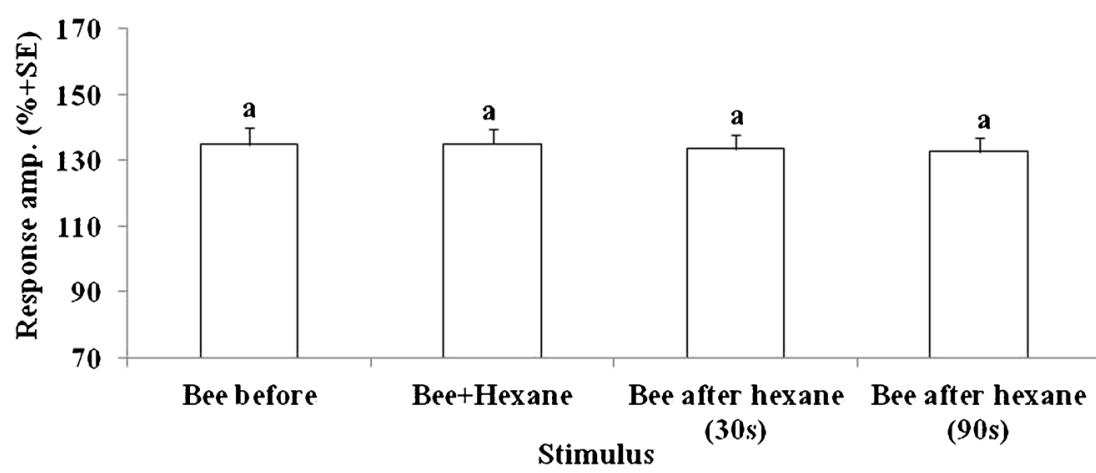

Figure 4. The longevity of the inhibitory effect of DEET on the electrotarsograms of the Varroa destructor to nurse bee headspace. The time interval between the mixed stimulus (nurse bee + DEET or control-hexane) and after the administration of the compound to a positive stimulus alone was varied. a Effect of $10 \mu \mathrm{g}$ DEET in $1 \mu \mathrm{L}$ hexane on the electrotarsograms with mite's forelegs to nurse bee headspace. b Effect of $1 \mu \mathrm{L}$ hexane (control) on the electrotarsograms of mite's forelegs to nurse bee headspace. Values are normalized against the response to air (\%, average $+\mathrm{SE})$ : bars marked by different letters indicate significant differences, ANOVA repeated measures, followed by a post hoc Tukey-Kramer test, $P<0.05 . n=6$.

in the foreleg following the same set of exposures to the solvent hexane $\left(F_{4,25}=0.13, P=0.97\right.$, ANOVA) (Figure 4b).

\subsection{Effect of DEET on the behaviour} of $V$. destructor

The mite choice for nurse or a forage bee was significantly dependent on the treatment. In the control group, mites started dispersing shortly after the beginning of the experiment, and about $63.4 \%$ of mites reached any of the host after $120 \mathrm{~min}$. Most of the mites reached a nurse bee (goodness of fit, $P<0.05$ ) (Figure 5). However, in the presence of 5 and $10 \mu \mathrm{g}$ DEET, the number of mites reaching any bee decreased significantly (goodness of fit, $P<0.05$ ) to 30 and $27 \%$, respectively. Moreover, in the presence of DEET, preference of $V$. destructor for a nurse bee was eliminated (goodness of fit, $P<0.05$ ). It is worth mentioning that despite of the fact that mites' dispersal started at the same time in treated and control group, some $V$. destructor exposed to DEET stopped moving after an hour.

\subsection{Effect of DEET on the behaviour of honey bee}

Our data clearly show that behaviour of nurse bees, exposed to DEET in the laboratory, was not dramatically affected. Significant attraction towards the queen was maintained by nurse bees, regardless of the presence of $100 \mu \mathrm{g}$ of DEET or control hexane (chi-square test for independence, 


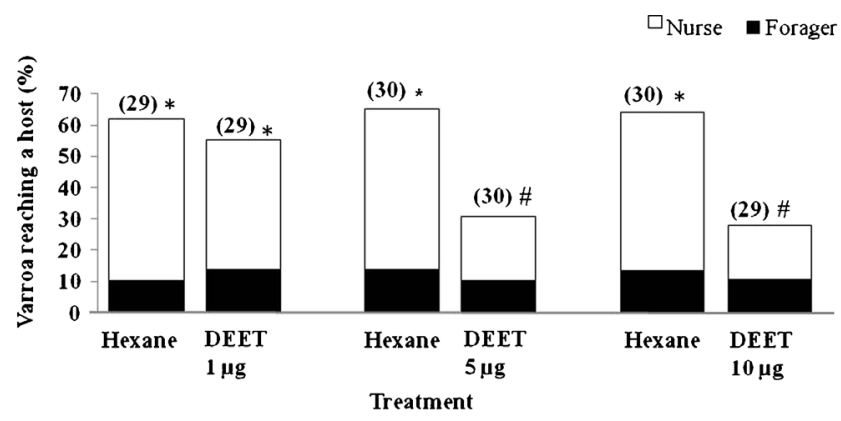

Figure 5. The effect of DEET on Varroa host choice between a nurse and a forager bee and Varroa destructor ability to reach any host. Data are the percentage of mites that selected a particular host 120 min from the beginning of the experiment in the presence of hexane (control) or DEET at different doses (1,5 and $10 \mu \mathrm{g})$. Numbers within the bars show the number of mites choosing each of the hosts. Asterisk indicates significant preference for a nurse over a forager bee per treatment and number sign indicates significant difference in total mites reaching any host between hexane and DEET (goodness of fit, $P<0.05$ ).

$P<0.05$ ) (Figure 6). We also evaluated the effect of DEET on general activity and interactions between the nurse bees. The duration of 11 activities, both social and general, was analysed. Social activities included touching each other's antennae, allogrooming (grooming between nestmates) and trophallaxis. General activities included walking, running, self-grooming, Nasanov gland exposure, standing, touching a lure, fanning and attempting flying (Figure 7). The results did not indicate any significant effect of DEET on the duration of the observed behaviours, in all tested doses $\left(F_{5,6}=0.83-3.17, P>0.05\right.$, ANOVA $)$.

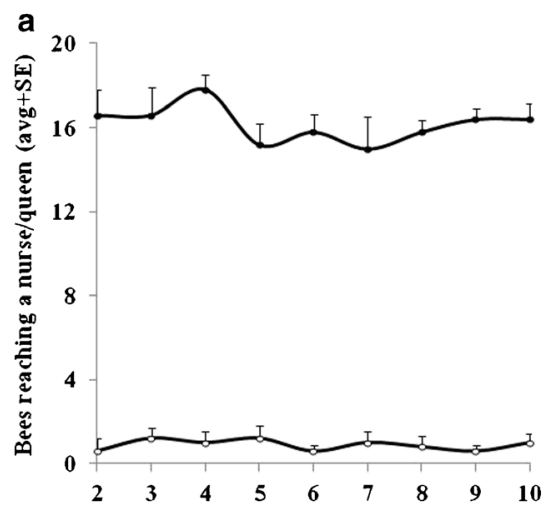

\section{DISCUSSION}

Disruption of host chemosensing is a first step in interference of host location by the parasite. However, as in this case the host is a social organism, it is vital to ensure the integrity of its communication that is mostly chemical. Hence, the present study has utilized electrophysiological and behavioural bioassays to test and compare the effect of DEET on the $V$. destructor and honey bee. It is well known that the honey bees are chemically sensed by its obligatory parasite, $V$. destructor, presumably through wall-pore

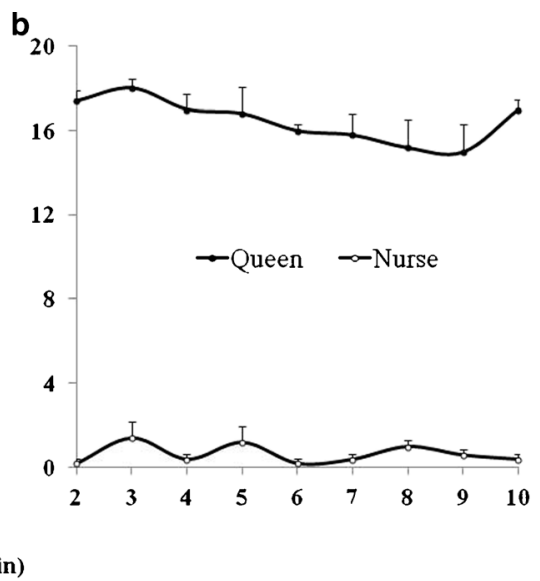

Figure 6. The Effect of DEET on attraction of nurse bees to a queen. The data are the average number of bees $+\mathrm{SE}$ (out of 20) that contacted the queen or the nurse bee over $10 \mathrm{~min}$ of observation in the presence of $100 \mu \mathrm{g}$ of DEET dissolved in $1 \mu \mathrm{L}$ hexane (a) or $1 \mu \mathrm{L}$ hexane as control (b). Significant preference for a queen was observed in both treated and control groups. Chi-square test for independence, $P<0.05(n=5)$. 


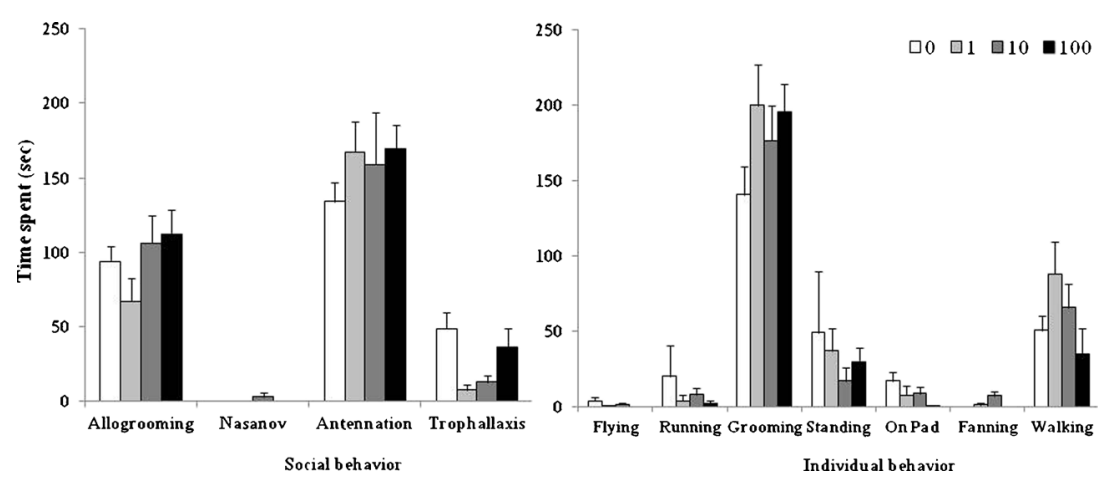

Figure 7. The effect of different doses of DEET on the duration of honey bee behaviours. The results are average duration of 5 bees exposed to 1,10 and $100 \mu \mathrm{g}$ of DEET dissolved in $1 \mu \mathrm{L}$ of hexane or $1 \mu \mathrm{L}$ of hexane (control). Each dose was tested in a different petri dish containing 5 nurse bees marked and observed individually. The experiment was replicated three times and the results are average of 15 bees. No significant difference was found between the different doses, ANOVA, $P>0.05$.

sensilla in the tarsal pit organ on the dorsal face of each front leg (Dillier et al. 2006), whereas honey bee mainly detects colony odours by sensilla placodea present in the periphery of the antennae (Esslen and Kaissling 1976). The dose response for the DEET on the bee antenna showed a dosedependent increase with the increase in the amount. On the other hand, $V$. destructor foreleg showed more or less an inconsistent response.

The mechanism by which DEET operates in different organisms is somewhat controversial. It has been suggested that it acts both at close range as a contact chemo-repellent on gustatory receptors and as a long-range odorant on olfactory system (Ditzen et al. 2008; Lee et al. 2010; Syed and Leal 2008). Although the role of gustatory receptors in the responses to DEET of $V$. destructor and honey bees is possible, our study reveals that DEET operates in the gas phase, activating the ORNs in honey bee antenna. The clear dose response to DEET by honey bee antennae indicates the presence of olfactory receptor neurons (ORNs) responsive to DEET, as was previously detected in mosquitoes (Stanczyk et al. 2010; Syed and Leal 2008). It has been suggested by Syed and Leal (2008) that DEET is recognized by ORNs that naturally respond to terpenoids. If the same mechanism is also true for honey bee ORNs, it fits well with the fact that terpenoids play an important role in honey bee biology, both within and outside of the colony (Winston 1987; Harrewijn et al. 2001). In contrast, no consistent response of the $V$. destructor foreleg to increasing doses of DEET may suggest that the mite lacks DEET-sensitive ORNs.

The next crucial question is whether DEET interferes with odour recognition by $V$. destructor and the honey bee and in particular blocks host recognition in $V$. destructor as it appears to be doing in mosquitoes and ticks (Fabbro and Nazzi 2013; Dickens and Bohbot 2013; Pellegrino et al. 2011). To test whether DEET can block host recognition by the mite and honey bee antenna, we evaluated its effect in combination with the respective positive stimulus. Two effects of DEET on the electrotarsogram and electroantennogram: short-term inhibition and long-term inhibition were evaluated. The inhibition observed in the presence of compound simultaneously with a positive stimulus was termed short-term inhibition, while inhibition that occurred following the administration of the compound alone was termed "long term inhibition". On the $V$. destructor foreleg, DEET caused only a long-term inhibition, while short-term effect was not significant. This effect was specific as no inhibition was observed to hexane. Short-term and long-term inhibition effects of DEET on antennal response to pheromones have been previously reported in the gypsy moth (Plettner and Gries 2010) and recently by us for the effect of other chemicals in $V$. destructor (Eliash et al. 2014). In contrast to the effect of DEET on $V$. destructor, the effect on honey bee antennae 
was transient (short term) and did not occur in subsequent positive stimulation. The mechanism behind the short- and long-term inhibitions on peripheral olfactory neurons in honey bee and in $V$. destructor is still unknown. However, some possible mechanisms have been previously suggested by Plettner and Gries (2010). These may include complex interaction within the ORN's machinery as well as between ORN and its environment. Additionally, independent studies in insects reviewed by Dickens and Bohbot (2013) have led to two distinct hypotheses on the molecular mode of action of DEET in olfaction: (i) DEET alone activates odorant-sensing subunit (ORx)-olfactory co-receptor (Orco) and inhibits ORx-Orco response to respective agonist and (ii) DEET appears to either inhibit or enhance the activation of an odorant receptor (OR) by the cognate ligand of that OR. Regarding mechanism behind long-term recovery, Plettner and Gries (2010) suggested that if recovery is inhibited, it may involve binding of the compound to another site; a candidate for this site maybe the $\mathrm{Na}^{+} / \mathrm{K}^{+}$ATPase or membrane $\mathrm{Ca}^{+}$ATPase (PMCA). The inhibition of these enzymes will prevent the recovery of the dendritic membrane potential. Thus, these possibilities need to be evaluated in future studies. Structure and function of olfactory machinery in Chelicerata in general and $V$. destructor in particular are yet to be discovered. So far, OR and Orco have not been reported in non-hexapods (Missbach et al. 2014) suggesting that the Orcobased mechanism described for DEET in insects (Ditzen et al. 2008) may not fit the olfactory system of the $V$. destructor. A second mechanism of action for DEET has recently been described in Drosophila : a particular variant ionotropic receptor (IR) appears to directly detect DEET and activate specific neurons (Kain et al. 2013). It is not known whether mites and $V$. destructor in particular have IRs, but the probability is high, given that these receptors have been found to be much more common than the OR/Orco system, e.g. in various arthropods, molluscs and nematodes (Croset et al. 2010).

The absolute duration of DEET inhibition is impossible to determine on $V$. destructor foreleg whose functions deteriorate within a rather short period of time, about half an hour. However, for comparison, it is important to note that the impact of DEET was so effective that it could not be eliminated by air stimulus, and it is comparable to the long-term effect of DEET on Lymantria dispar reported by Plettner and Gries (2010). Although the olfactory signals normally undergo neural processing and behavioural effect cannot be reliably predicted based on electrophysiological response of the peripheral olfactory organ, in this case, olfactory long-term inhibition correlated with behavioural data. In a control-choice experiment, the mites preferred nurse bees over foragers as expected according to Nazzi et al. (2001). In its simplest form, the disruption of host recognition is expected to result in a lack of host preference. This was exactly the result. In presence of DEET, no preference was observed. In fact, although mites' dispersal started at the same time in treated and control groups, a similar number of mites reached both bee types. Moreover, the majority did not reach any of the hosts. Some $V$. destructor exposed to DEET even stopped moving after an hour. The reason for mites' disorientation is yet unclear; however, we can suggest that it is the result of DEET blockage of host recognition. This mechanism seems to differ for the effect of 5(2'methoxyethyl)cyclopent-2-en-1-butoxyl diether and 1,3-diethoxybenzene that cause change in the mites' host preference, from nurse to forager bee (Eliash et al. 2014). Could it be that $V$. destructor stopped moving due to paralysis caused to it by DEET? Beside its direct effect on peripheral olfactory system, DEET is known to inhibit acetylcholinesterase in insects (Corbel et al. 2009). This enzyme is involved in the hydrolysis of the neurotransmitter acetylcholine, which, if not broken down, leads to an excessive accumulation of acetylcholine at the synaptic cleft, causing neuromuscular paralysis. Yet, as leg movement of $V$. destructor was confirmed by contact with a paint brush at end of the experiment, it appears that paralysis of legs did not occur, and the reason for mites not reaching a host is due to their inability to orient to host odours. The apparent long-term effect of DEET on $V$. destructor and the merely shortterm inhibition of chemosensing in the honey bee antenna in response to queen bee headspace signified that DEET is a good candidate for further studies on its effect on honeybees. 
Due to the fact that DEET is sensed by honeybees, as shown above, and chemical communication is at the core of coordination of colonial activity of this superorganism, the clarification of the effects of DEET on honey bees is crucial. It appears that DEET spray is used as a bee repellent in some European countries during honey harvesting (Schroeder et al. 2007). Still, so far only two studies addressed the effect of DEET on honey bees. In both studies, only the repellent effect of DEET on guard bees was tested. While one study showed significant repellence effect of DEET to both European and Africanized bees (Collins et al. 1996). The later study by Schmidt et al. (2003) showed that behaviour of Africanized bees was not significantly affected by DEET, albeit some decrease in bee attack behaviour could be observed. Our results of the queen attraction assay and nurse bee behaviour in the presence of DEET lead us to conclude that DEET does not obstruct chemical communication between the nurse bees or between the latter and their queen. This is consistent with our electrophysiological finding that DEET had no long-term effect on the responses of nurses to queen bee headspace. In conclusion, this study shows a dramatic effect of DEET on $V$. destructor chemosensing and host location, preventing mites from reaching its host in the laboratory conditions. This finding indicates the potential of a compound with such an effect for $V$. destructor control. Still, DEET effect on $V$. destructor population at the honeybee level colony remains to be tested along with its safety for the bees and the residue levels in the bee products. The problem with DEET residue accumulation in wax and honey following DEET spray during honey harvest was previously reported (Schroeder et al. 2007). Our particular concerns relate to the facts that DEET is sensed by honey bees and may also be absorbed into the body of honey bees via other routes, with still unknown effects. Moreover, elucidation of the molecular mechanism behind the effect of DEET at the sensory organ of the $V$. destructor foreleg and honey bee antennae is essential and may serve as a model contributing significantly to the development of new powerful tools for disruption of $V$. destructor chemosensing for its sustainable management even if DEET itself will be found unsuitable for this purpose. Whatever is the disruptive compound, the future of Varroa control is apparently integrated management, in which behavioural modifiers interrupting the host recognition and inhibiting bee colonization by Varroa are expected to play a significant role along with other means such as bee breeding for hygienic behaviour.

\section{ACKNOWLEDGMENTS}

We thank Miss Yafit Brenner for providing us with dedicated program for behavioural analysis and Dr. Ada Rafaeli (Agricultural Research Organization, The Volcani Center) for stimulating discussions during manuscript preparation. We also wish to thank the anonymous reviewers for the valuable comments and suggestions. This project was supported by the Jewish Charitable Association, grant no 131-1740, and subsequently by grant from the Chief Scientist Ministry of Agriculture, grant no. 131-1815. We are also thankful to the Agricultural Research Organization, The Volcani Center, Bet Dagan, Israel for providing postdoctoral fellowship to Dr. Nitin Kumar Singh.

Effet du DEET sur la sensibilité chimique de l'abeille et de son parasite Varroa destructor

N,N-diéthyl-m-toulamide / Apis mellifera ligustica / électroantennogramme / essai biologique comportement / inhibition à court terme / inhibition à long terme

Der Effekt von DEET auf die Chemosensorik von Honigbienen und ihrem Parasiten Varroa destructor

N,N-Diethyl-m-Toulamid / Apis mellifera ligustica / Elektroantennogramm / Verhaltensbiotest / KurzzeitInhibition / Langzeit-Inhibition

\section{REFERENCES}

Carroll, J.F., Benante, J.P., Klun, J.A., White, C.E., Debboun, M., Pound, J.M., Dheranetra, W. (2008) Twelve-hour duration testing of cream formulations of three repellents against Amblyomma americanum. Med. Vet. Entomol. 22, 144-151

Collins, A.M., Rubnik, W.L., Aguilar, J.I.C., Hellmich, R.L. (1996) Use of Insect Repellents for Dispersing Defending Honey Bees (Hymenoptera: Apidae). J. Econ. Entomol. 89, 608-613 
Corbel, V., Stankiewicz, M., Pennetier, C., Fournier, D., Stojan, J., Girard, E., Dimitrov, M., Molgó, J., Hougard, J.M., Lapied, B. (2009) Evidence for inhibition of cholinesterases in insect and mammalian nervous systems by the insect repellent Deet. BMC Biol. 47, 1-11

Croset, V., Rytz, R., Cummins, S.F., Budd, A., Brawand, D., Kaessmann, H., Gibson, T.J., Benton, R. (2010) Ancient protostome origin of chemosensory ionotropic glutamate receptors and the evolution of insect taste and olfaction. PLoS Genet. 6, 1-20

Del Piccolo, F., Nazzi, F., Della Vedova, G., Milani, N. (2010) Selection of Apis mellifera workers by the parasitic mite Varroa destructor using host cuticular hydrocarbons. Parasitology 137, 967-973

Dickens, J.S., Bohbot, J.D. (2013) Mini review: Mode of action of mosquito repellents. Pesticide Biochem Physiol. 106, 149-155

Dillier, F.X., Fluri, P., Imdorf, A. (2006) Review of the orientation behaviour in the bee parasitic mite Varroa destructor: sensory equipment and cell invasion behavior. Revue Suisse de Zoologie. 113, 857-877

Ditzen, M., Pellegrino, M., Vosshall, B.L. (2008) Insect odorant receptors are molecular targets of the insect repellent DEET. Science 319, 1838-1842

Eliash, N. (2012) Learning and disrupting the chemical communication of Varroa destructor Anderson and Trueman. M.Sc. Thesis, Robert H. Smith Faculty of Agriculture, Food and Environment of the Hebrew University of Jerusalem, Israel

Eliash, N., Singh K. N., Kamer Y., Plettner, E., Soroker, V. (2014) Can we disrupt the sensing of honey bees by the bee parasite Varroa destructor? PLoS One, in press

Ess le n, J ., Ka is s ling, K. E. ( 1976 ) ZahlundVerteilungantennalerSen- sillen beider Honigbiene (Apis mellifera L.). Zoomorphologie 83, 227-251

Fabbro, S.D., Nazzi, F. (2013) From Chemistry to Behavior. Molecular Structure and Bioactivity of Repellents against Ixodes ricinus Ticks. PLoS One 8, 1-9

Harrewijn, P., van Oosten, A.M., Piron, P.G. (2001) Natural Terpenoids as Messengers: A Multidisciplinary Study of Their production, biological Functions and Practical Applications. Kluwer Academic Publishers., Netherlands

Kain, P., Boyle, S.M., Tharadra, S.K., Guda, T., Pham, C., Dahanukar, A., Ray, A.(2013) Odour receptors and neurons for DEET and new insect repellents. Nature $\mathbf{5 0 2}, 507-514$

Klun, J.A., Khrimian, A., Debboun, M. (2006) Repellent and deterrent effects of SS220, Picaridin, and DEET suppress human blood feeding be Aedes aegypti, Anopheles stephensi, and Phlebotomus papatasi . J Med. Entomol. 43, 34-39

Kraus, B. (1993) Preferences of Varroa jacobsoni for honey bee (Apis mellifera L.) of different ages. J Apic. Res. 32, 57-64

Le Conte, Y., Arnold, G., Trouiller, J., Masson, C., Chappe, B., Ourisson, G. (1989) Attraction of the parasitic mite Varroa to the drone larvae of honey bees by simple aliphatic esters. Science 245, 638-639
Lee, Y., Kim, S.H., Montell, C. (2010) Avoiding DEET through insect gustatory receptors. Neuron 67, 55515561

Martin, S.J. (2001) Biology and life history of Varroa mites. In: Webster TC, Delaplane KS. (Eds.) Mites of the Honey Bee. Hamilton: Dadant Sons. pp. 131-148

Missbach, C., Dweck, H.K., Vogel, H., Vilcinskae, A., Stensmyr, M.C., Hansson, B.S., Grosse-Wilde, E. (2014) Evolution of insect olfactory receptors. Elife 3, 1-22

Nazzi, F., Milani, N., Vedova, G.D., Nimis, M. (2001) Semiochemicals from larval food affect the locomotory behaviour of Varroa destructor. Apidologie 32 , 149-155

Pellegrino, M., Steinbach, N., Stensmyr, M.C., Hansson, B.S., Vosshall, L.B. (2011) A natural polymorphism alters odour and DEET sensitivity in an insect odorant receptor. Nature 478, 511-514

Pernal, S.F., Baird, D.S., Birmingham, A.L., Higo, H.A., Slessor, K.N., Winston, M.L. (2005) Semiochemicals influencing the host-finding behaviour of Varroa destructor. Exp Appl Acarol. 37, 1-26

Plettner, E., Gries, R. (2010) Agonists and antagonists of antennal responses of gypsy moth (Lymantria dispar) to the pheromone $(+)$-disparlure and other odorants. J. Agric. Food Chem. 58, 3708-3719

Rosenkranz, P., Aumeier, P., Ziegelmann, B. (2010) Biology and control of Varroa destructor. J Invertebr. Pathol. 103, S96-S119

Sandoz, J.C. (2011) Behavioral and neurophysiological study of olfactory perception and learning in honey bee. Front Syst Neurosci. 5, 1-20

Schmidt, J.O., Johnston, A.N., Ginter, D.L., Spangler, H.G. (2003) Olfactory stimulation of Africanized honey bee (Hymenoptera: Apidae) attacks by insect repellents. J. Med. Entomol. 40, 275-278

Schroeder, A., Fritz, B., Weber, D., Wallner, K. (2007) A bee repellent endangers the quality of bee products. Apidologie 38, 495-496

Stanczyk, N.M., Brookfield, J.F., Ignell, R., Logan, J.G., Field, L.M. (2010) Behavioral insensitivity to DEET in Aedes aegypti is a genetically determined trait residing in changes in sensillum function. Proc. Natl Acad. Sci. USA. 107, 8575-8580

Stanczyk, N.M., Brookfield, J.F., Field, L.M., Logan, J.G. (2013) Aedes aegypti mosquitoes exhibit decreased repellency by DEET following previous exposure. PLoS One 8, 1-6

Syed, Z., Leal, W.S. (2008) Mosquitoes smell and avoid the insect repellent DEET. Proc. Natl Acad. Sci. USA. 105, 13598-13603

Torto, B., Carroll, M.J., Duehl, A., Fombong, A.T., Gozansky, T. K., Nazzi, F., Soroker, V., Teal, P.E.A. (2013) Standard methods for chemical ecology research in Apis mellifera. J. Apic. Res. 52, 1-34

Winston, M.L. (1987) The Biology of the Honey Bee. Harvard University Press., Cambridge, MA. 